Quality Choice and Advertising Regulation in Broadcasting Markets 
Los documentos de trabajo del Ivie ofrecen un avance de los resultados de las investigaciones económicas en curso, con objeto de generar un proceso de discusión previo a su remisión a las revistas científicas. Al publicar este documento de trabajo, el Ivie no asume responsabilidad sobre su contenido.

Ivie working papers offer in advance the results of economic research under way in order to encourage a discussion process before sending them to scientific journals for their final publication. Ivie's decision to publish this working paper does not imply any responsibility for its content.

La Serie $\mathrm{AD}$ es continuadora de la labor iniciada por el Departamento de Fundamentos de Análisis Económico de la Universidad de Alicante en su colección "A DISCUSIÓN" y difunde trabajos de marcado contenido teórico. Esta serie es coordinada por Carmen Herrero.

The AD series, coordinated by Carmen Herrero, is a continuation of the work initiated by the Department of Economic Analysis of the Universidad de Alicante in its collection "A DISCUSIÓN", providing and distributing papers marked by their theoretical content.

Todos los documentos de trabajo están disponibles de forma gratuita en la web del Ivie http:/ / www.ivie.es, así como las instrucciones para los autores que desean publicar en nuestras series.

Working papers can be downloaded free of charge from the Ivie website http://www.ivie.es, as well as the instructions for authors who are interested in publishing in our series.

Versión: febrero 2012 / Version: February 2012

Edita / Published by: Instituto Valenciano de Investigaciones Económicas, S.A. C/ Guardia Civil, 22 esc. $21^{\circ}$ - 46020 Valencia (Spain) 
WP-AD 2012-03

\title{
Quality Choice and Advertising Regulation in Broadcasting Markets
}

\author{
Miguel González-Maestre and Francisco \\ Martínez-Sánchez ${ }^{* *}$
}

\begin{abstract}
We consider the role of the endogenous choice of platform quality in a broadcasting duopoly market where competing media platforms choose also their level of advertising. We compare the equilibrium levels of quality, advertising and welfare under private and mixed duopoly competition. We show that the welfare comparison between the private and mixed duopoly regimes depends, crucially, on the interplay between the net direct effect of advertising on welfare and the degree of substitutability between platforms. We also consider the effects on quality and welfare of recent policies tending to eliminate advertising as a way of financing publicly-owned platforms.
\end{abstract}

Keywords: endogenous quality, two-sided markets, broadcasting duopoly, publicly-owned platform, advertising regulation.

JEL classification: L11, L33, L82, M37.

\footnotetext{
* The first author acknowledges financial support from Fundación Séneca, Agency of Science and Technology of the Region of Murcia, under project 11885/PHCS/09 and the Spanish Ministry of Science and Innovation under project ECO2009-07616/ECON, and the second acknowledges financial support from the Spanish MICINN under Project ECO2010-19830.

** M. González-Maestre, Departamento de Fundamentos del Análisis Económico, Universidad de Murcia; F. MartínezSánchez, Departamento de Métodos Cuantitativos para la Economía y la Empresa, Universidad de Murcia, Spain, corresponding author: fms@um.es.
} 


\section{Introduction}

In the context of a free-to-air broadcasting industry, the objective of this paper is to investigate the role of a publicly-owned platform and the regulation of advertising levels, assuming the endogenous choice of platforms' quality. As pointed out by Coase (1966), in this industry, the public policy might have an important role in regulating the quality and diversity of the available programming, as well as the level of advertising. However, despite of the empirical relevance of the presence of publicly-owned platforms in the media industries of many western countries, there is a surprising lack of research about this form of public intervention in broadcasting markets. Nevertheless, there are some recent exceptions. On the theoretical side, the work by Kind et al. (2007), consider a mixed oligopoly with horizontal differentiation, while González-Maestre and Martínez-Sánchez (2010) focus on a mixed duopoly with both horizontal and vertical differentiation but with exogenous qualities, showing the crucial relevance of the quality differential among platforms in the welfare results. Regarding the empirical contributions, Alcock and Docwra (2005) develop an stochastic oligopoly model for the Australian broadcasting market, and Bel and Domènech (2009) analyzes the advertising prices in the Spanish broadcasting industry.

Our contribution is related with some recent empirical literature dealing with the importance of platform's quality in television markets. In particular, the work by Beard et al. (2001) gauges that the increase in consumer gains due to a quality increase are almost exactly counterbalanced by reductions due to price increases. Chu (2010) studies the cable television market and finds that satellite entry typically causes cable platforms to raise quality and lower prices. Finally, Imbs et al. (2010) study television prices across European countries and regions. They show that a large fraction of international price gaps corresponds to quality differences. On the theoretical side, the analysis of advertising in broadcasting media industries, with private platforms, has been extensively considered in recent literature. ${ }^{1}$ Most of these previous contributions focus on the combination of advertising and horizontal product differentiation among private platforms in two-sided markets. In particular, Gabszewicz et al. (2004) and Anderson and Coate (2005) consider the role of platform substitutability on the equilibrium and socially optimal

\footnotetext{
${ }^{1}$ See the interesting surveys about advertising in the media by Anderson (2007) and Anderson and Gabszewicz (2006).
} 
levels of advertising; Gantman and Shy (2007) analyze the profitability of improvements in advertising quality and Peitz and Valletti (2008) compares the levels of advertising intensities and content differentiation under two different scenarios: pay-tv and free-to-air. In the recent work by Lin (2011), this author considers a private duopoly with endogenous choice of quality by TV platforms, analyzing different outcomes depending on the presence of free-based or pay TV platforms.

The aim of our paper is twofold:

First, we will analyze the combined role of the endogenous choice of platform quality and the presence of a publicly-owned platform in the broadcasting industry. In previous contributions, Armstrong (2005) and more recently Crampes et al. (2009), those authors analyze the effects of endogenous quality improvements in broadcasting industries. In particular, Armstrong compares the equilibrium quality levels between the free-to-air duopoly regime and the case of subscription, while Crampes et al. (2009) analyze the effects of endogenous quality improvements under free entry. However, these previous contributions assume competition among symmetric private platforms while we consider the case of a publicly-owned platform competing with a private one. We compare the equilibrium levels of platforms qualities and advertising under private and mixed duopoly competition, and show that the results are drastically different between both scenarios

Second, we also consider the effects on platform quality and welfare of recent policies tending to eliminate advertising as a way of financing publiclyowned platforms. This aspect of our analysis is related with some recent controversial policy decisions within the EU. Particularly remarkable is the decision by the public TV platform in France (more recently followed by its counterpart in Spain) of eliminating advertising as a way of financing. In substitution of this source of financing, the French government has established a tax on the revenues by private TV and telecom platforms, a decision which is currently under investigation by the European Commission. ${ }^{2}$

The rest of the paper is organized as follows: Section 2 presents a spacial duopoly market with private platforms and endogenous choice of advertising and quality, Section 3 analyzes a duopoly model where one of the competitors is a publicly-owned platform that maximizes welfare, Section 4 analyzes the

\footnotetext{
${ }^{2}$ Regarding advertising regulation, recently, Stümeier and Wenzel (2011) evaluate the effects of a binding advertising cap on competition for viewers and advertisers in a private duopoly model. They obtain that regulation of advertising can increase platforms' profits.
} 
controversial policy decisions within the EU carried out by France and Spain of eliminating advertising as a way of financing the public platform, Section 5 considers the advertising, platform quality and welfare comparisons among the three regimes and Section 6 concludes.

\section{The private duopoly model}

There are two private platforms, 1 and 2, which are located, respectively, at the extreme left and right of a linear market of length $1 .^{3}$ There is a mass of consumers of measure 1 indexed by $x \in[0,1]$ and distributed uniformly along this linear market. Each consumer chooses either one unit of good or zero. The utility of consumer $x$ if she/he watches platform $i$ is given by the function

$$
u(x)=\left\{\begin{array}{cc}
v_{1}-\delta a_{1}-t x & \text { if } i=1, \\
v_{2}-\delta a_{2}-t(1-x) & \text { if } i=2,
\end{array}\right.
$$

where $v_{i}$ is the gross utility from the chosen platform, $\delta$ is the parameter representing the disutility or nuisance cost per unit of advertising (denoted by $\left.a_{i}\right)^{4}$ and $t$ is the transport cost per unit of the distance of departing from her/his favorite TV platform. Moreover, $t$ can be interpreted as the degree of horizontal differentiation, so a higher $t$ means that platforms are least substitutable.

Let us define by $x_{1}$ as the marginal consumer who is indifferent between watching platforms 1 and 2. Similarly, we define $x_{2}=1-x_{1}$. From the utility function (1), we obtain the audience share for platform $i$, which is given by:

$$
x_{i}\left(a_{i}, a_{j}\right)=\frac{v_{i}-v_{j}+t-\delta\left(a_{i}-a_{j}\right)}{2 t}, i=1,2, j \neq i .
$$

As in Gabszewicz et al. (2004) we consider that the advertising market is perfectly competitive, so advertisers' profits are zero. We assume that the advertising revenues obtained by platform $i$ are given by $R_{i}=\gamma a_{i} x_{i}$, where $\gamma$ can be interpreted as the revenue per ad per viewer. On the other hand, the

\footnotetext{
${ }^{3}$ As it is usual in horizontal differentiation models, the commodity space allows a wide range of interpretations, including ideological preferences or entertainement tastes.

${ }^{4}$ Our assumption that $\delta>0$ is consistent with the empirical evidence shown by Wilbur (2008). This author obtains that viewers dislike advertising in the TV industry.
} 
cost of achieving a quality $v_{i}$ for platform $i$ is given by the quadratic function $C\left(v_{i}\right)=\frac{v_{i}^{2}}{2}$. Thus, profits of platform $i$ are given by:

$$
\pi_{i}=\gamma a_{i} x_{i}-\frac{v_{i}^{2}}{2}, i=1,2, i \neq j .
$$

By substituting the demand function (2) in the profit function (3), we can obtain:

$$
\pi_{i}\left(a_{i}, a_{j}\right)=\gamma a_{i}\left(\frac{1}{2}+\frac{v_{i}-v_{j}-\delta\left(a_{i}-a_{j}\right)}{2 t}\right)-\frac{v_{i}^{2}}{2}, i=1,2, i \neq j .
$$

We assume a two-stage game where, first, the platforms choose, simultaneously, their levels of quality and in the second stage they choose the advertising levels. Let us obtain the Nash equilibrium (NE) in the levels of advertising at the second stage of the game. From the first order conditions, we can obtain the reaction function of each platform:

$$
a_{i}\left(a_{j}\right)=\frac{v_{i}-v_{j}+t}{2 \delta}+\frac{a_{j}}{2}, i=1,2, i \neq j .
$$

Which yields the following NE levels of advertising and market shares at the second stage of the game:

$$
a_{i}=\frac{v_{i}-v_{j}+3 t}{3 \delta} ; \quad x_{i}=\frac{v_{i}-v_{j}+3 t}{6 t} ;
$$

By substituting (6) in (4), we find the following expression for platform $i$ 's profit, evaluated at the first stage of the game:

$$
\pi_{i}\left(v_{i}, v_{j}\right)=\frac{k\left(v_{i}-v_{j}+3 t\right)^{2}}{18 t}-\frac{v_{i}^{2}}{2}, \quad i=1,2, i \neq j,
$$

where $k \equiv \gamma / \delta$ is the ratio of the revenue per ad per viewer and the nuisance cost. If $k<1$ (respectively $k>1$ ), the negative impact of advertising on consumers' utility is greater (lower) than the positive impact of advertising on the platform's revenue. Therefore, the direct net effect of advertising on welfare is negative (respectively positive) if $k<1(k>1)$, while $k=1$ is the case where advertising is neutral from the welfare point of view.

The first order conditions of profit maximization yield the following reaction functions of platforms, in terms of quality choices: 


$$
v_{i}\left(v_{j}\right)=\frac{\left(3 t-v_{j}\right) k}{9 t-k} ; \quad i=1,2, \quad i \neq j .
$$

Solving the above equations gives the subgame perfect equilibrium (SPE) levels of qualities, advertising, market shares and profits:

$$
v_{i}^{P}=\frac{k}{3} ; a_{i}^{P}=\frac{t}{\delta} ; x_{i}^{P}=\frac{1}{2} ; \pi_{i}^{P}=\frac{(9 t-k) k}{18}, i=1,2 .
$$

As can be seen from (9), in equilibrium both platforms choose the same quality and ads, so that they obtain the same demand and profit. We also find that profits are increasing in $k$. This is because platforms' profitability of quality improvement positively depends on $k$, which is reflected in the fact that equilibrium qualities are increasing in $k$. Finally, we find that the level of quality does not depend on the degree of substitutability.

Consumer surplus $(C S)$ is calculated as: ${ }^{5}$

$$
C S=v_{1} x_{1}-\delta a_{1} x_{1}-t \int_{0}^{x_{1}} x d x+v_{2}\left(1-x_{1}\right)-\delta a_{2}\left(1-x_{1}\right)-t \int_{x_{1}}^{1}(1-x) d x .
$$

We now calculate social welfare $(W)$, defined as the sum of platforms' profits $\left(\pi=\pi_{1}+\pi_{2}\right)$ and consumer surplus $(C S)$,

$$
W=(\gamma-\delta) a_{2}+\left(v_{1}-v_{2}+t+(\gamma-\delta)\left(a_{1}-a_{2}\right)\right) x_{1}-t x_{1}^{2}+v_{2}-\frac{t+v_{1}^{2}+v_{2}^{2}}{2}
$$

By using (9) in (11), we obtain the social welfare at the SPE in the private duopoly, which is given by:

$$
W^{P}=\frac{(36 k-45) t-4\left(k^{2}-3 k\right)}{36} .
$$

\section{The mixed duopoly model}

In this section, we will assume that platform 1 is a publicly-owned firm that maximizes social welfare, while platform 2 is a private firm that maximizes its profit. Substituting (2) in (11) and maximizing the resulting welfare function

\footnotetext{
${ }^{5}$ Recall that $x_{2}=1-x_{1}$.
} 
with respect to $a_{1}$, we obtain the reaction function of the publicly-owned platform 1:

$$
a_{1}\left(a_{2}\right)=a_{2}+\frac{k-1}{\delta(2 k-1)}\left(v_{1}-v_{2}+t\right) .
$$

In order to guarantee the second order condition of social welfare maximization by platform 1 , we assume that $k>1 / 2$. Notice that platform 2 's reaction function is the same that the one in the previous section since it continues to be a private firm. Thus, from (5) and (13) we can calculate the second stage NE levels of advertising and market shares in the mixed duopoly:

$$
\begin{aligned}
& a_{1}=\frac{(4 k-3) t-\left(v_{1}-v_{2}\right)}{\delta(2 k-1)} ; a_{2}=\frac{(3 k-2) t-k\left(v_{1}-v_{2}\right)}{\delta(2 k-1)} \\
& x_{1}=\frac{k\left(v_{1}-v_{2}+t\right)}{2(2 k-1) t} ; x_{2}=\frac{(3 k-2) t-k\left(v_{1}-v_{2}\right)}{2(2 k-1) t} ;
\end{aligned}
$$

By substituting the NE values of market shares and advertising of platforms 1 and 2 into expressions (3) and (11) we obtain the profits functions and the welfare at the first stage of the game, in terms of the qualities:

$$
\begin{gathered}
\pi_{1}=\frac{k^{2}\left((4 k-3) t-\left(v_{1}-v_{2}\right)\right)\left(v_{1}-v_{2}+t\right)}{2(2 k-1)^{2} t}-\frac{v_{1}^{2}}{2} ; \pi_{2}=\frac{k\left((3 k-2) t-k\left(v_{1}-v_{2}\right)\right)^{2}}{2(2 k-1)^{2} t}-\frac{v_{2}^{2}}{2} \\
W=\frac{4(k-1)\left((3 k-2) t-k\left(v_{1}-v_{2}\right)\right) t+k^{2}\left(v_{1}-v_{2}+t\right)^{2}}{4(2 k-1) t}+v_{2}-\frac{t}{2}-\frac{v_{1}^{2}}{2}-\frac{v_{2}^{2}}{2} .
\end{gathered}
$$

By maximizing the social welfare with respect to $v_{1}$, we obtain the reaction function of the publicly-owned platform, $v_{1}\left(v_{2}\right)$, and, by maximizing platform 2's profit with respect to $v_{2}$, we find the reaction function of the private platform, $v_{2}\left(v_{1}\right)$. Those functions are given by:

$$
v_{1}\left(v_{2}\right)=\frac{k^{2} t+k^{2} v_{2}-2 k t}{2 t-4 k t+k^{2}} ; v_{2}\left(v_{1}\right)=-\frac{2 k^{2} t-3 k^{3} t+k^{3} v_{1}}{t+4 k^{2} t-4 k t-k^{3}}
$$

Thus, from (16) we calculate the SPE levels of quality, advertising, market shares, platform 2's profit and welfare in the mixed duopoly:

$$
\begin{aligned}
v_{1}^{M} & =\frac{9 k^{2} t-12 k^{3} t+4 k^{4} t-2 k t+2 k^{5}}{2 t+24 k^{2} t-16 k^{3} t-12 k t+k^{2}-6 k^{3}+8 k^{4}} \\
v_{2}^{M} & =\frac{2 k^{5}-12 t k^{4}+14 t k^{3}-4 t k^{2}}{2 t+24 k^{2} t-16 k^{3} t-12 k t+k^{2}-6 k^{3}+8 k^{4}}
\end{aligned}
$$




$$
\begin{gathered}
a_{1}^{M}=\frac{2 t(2 k-1)\left(k-3 t+4 k t-2 k^{2}\right)}{2 t \delta+k^{2} \delta-4 k^{3} \delta-8 k t \delta+8 k^{2} t \delta} ; a_{2}^{M}=\frac{-2 k^{3} t+12 k^{2} t^{2}-14 k t^{2}+4 t^{2}}{2 t \delta+k^{2} \delta-4 k^{3} \delta-8 k t \delta+8 k^{2} t \delta} \\
x_{1}^{M}=-\frac{k t-2 k^{2} t-k^{2}+3 k^{3}}{2 t+8 k^{2} t-8 k t+k^{2}-4 k^{3}} ; x_{2}^{M}=\frac{-k^{3}+6 t k^{2}-7 t k+2 t}{2 t+8 k^{2} t-8 k t+k^{2}-4 k^{3}} \\
\pi_{2}^{M}=\frac{2 k\left(-k^{3}+4 t k^{2}-4 t k+t\right)\left(-k^{3}+6 t k^{2}-7 t k+2 t\right)^{2}}{(2 k-1)^{2}\left(2 t+8 k^{2} t-8 k t+k^{2}-4 k^{3}\right)^{2}} \\
\quad \Omega(k, t) \\
W^{M}=-\frac{2(2 k-1)^{2}\left(2 t+8 k^{2} t-8 k t+k^{2}-4 k^{3}\right)^{2}}{2(2 k}
\end{gathered}
$$

where

$$
\Omega(k, t) \equiv\left(\begin{array}{c}
8 k^{8}\left[98 t-(30 t+4) k+k^{2}+108 t^{2}+3\right] \\
-2 k^{6}\left[2 k+(460 k-249) t+(1608 k-2390) t^{2}+16 t^{3}(26 k-113)\right] \\
+k^{4} t\left[11-124 k+(1561-3680 k) t+(6480-6560 k) t^{2}\right] \\
-2 t^{2}\left[(124 k-10) t-(653 t+16) k^{2}+(1890 t-174) k^{3}\right]
\end{array}\right)
$$

\section{The case of zero advertising commitment by the public platform}

In this section we evaluate the consequences of the new regulation introduced in the TV broadcasting industry by the French and Spanish governments. Thus we will assume that the publicly-owned platform is committed to set zero advertising $\left(a_{1}=0\right)$. Therefore, the timing is similar to the previous game, except that at the advertising stage only the private platform chooses its level of advertising. To simplify the terminology, in the rest of the paper, we will define the case analyzed in this section as the zero duopoly regime. ${ }^{6}$

By substituting the demand function (2) in the definition of profits and taking into account that $a_{1}=0$, we can obtain:

\footnotetext{
${ }^{6}$ Apart from eliminating the advertising in the publicly-owned platform, the French and Spanish regulation involves a tax on the revenue obtained by the private platforms. However, in order to simplify the exposition of the paper, we assume that the government set a tax equal to zero, which is an equilibrium in the game where the government can set a tax on the private platform's revenue. The resolution of this game is relegated to the Appendix.
} 


$$
\pi_{1}=-\frac{v_{1}^{2}}{2} ; \quad \pi_{2}=\gamma a_{2} \frac{v_{2}-v_{1}+t-\delta a_{2}}{2 t}-\frac{v_{2}^{2}}{2} .
$$

From maximizing the private platform's profit, we can obtain the private platform 2's advertising level, so:

$$
a_{2}=\frac{v_{2}-v_{1}+t}{2 \delta}
$$

By substituting the level of advertising (18) in the profit functions (17) we obtain the profits:

$$
\pi_{1}=-\frac{v_{1}^{2}}{2} ; \quad \pi_{2}=\frac{k\left(v_{2}-v_{1}+t\right)^{2}}{8 t}-\frac{v_{2}^{2}}{2} .
$$

We now consider the platforms' quality choices, so the publicly-owned platform maximizes the social welfare and the private one maximizes her/his profit. Taking into account that platform 1 does not obtain any revenue from advertising, the social welfare $(W)$ at the first stage is now given by:

$$
W=v_{2}-\frac{t}{2}+\frac{\left(v_{1}-v_{2}+3 t\right)\left(3\left(v_{1}-v_{2}\right)+t\right)}{16 t}+\frac{(k-1)\left(v_{2}-v_{1}+t\right)^{2}}{8 t}-\frac{v_{1}^{2}}{2}-\frac{v_{2}^{2}}{2},
$$

where the platforms' profits $(\pi)$ and consumer surplus $(C S)$ are given by:

$$
\begin{gathered}
\pi=\pi_{1}+\pi_{2}=\frac{k\left(v_{2}-v_{1}+t\right)^{2}}{8 t}-\frac{v_{1}^{2}}{2}-\frac{v_{2}^{2}}{2} \\
C S=v_{2}-\frac{t}{2}+\frac{\left(v_{1}-v_{2}+3 t\right)\left(3\left(v_{1}-v_{2}\right)+t\right)}{16 t}-\frac{\left(v_{2}-v_{1}+t\right)^{2}}{8 t}
\end{gathered}
$$

From the first order conditions in the first stage of the game, we can obtain the reaction function of each platform:

$$
v_{1}\left(v_{2}\right)=\frac{(2 k-7) t+(2 k+1) v_{2}}{2 k-8 t+1} ; \quad v_{2}\left(v_{1}\right)=\frac{\left(t-v_{1}\right) k}{4 t+k} .
$$

From the intersection of platforms' quality reaction functions, we obtain the levels of advertising, market shares and profits at the SPE of this game: 


$$
\begin{aligned}
v_{1}^{Z} & =\frac{2 k+(2 k-7) t}{4 k+1-8 t} ; v_{2}^{Z}=\frac{-2 k(t-1)}{4 k-8 t+1} ; a_{1}^{Z}=0 ; a_{2}^{Z}=\frac{-4 t(t-1)}{(1+4 k-8 t) \delta} \quad(21) \\
x_{1}^{Z} & =-\frac{6 t-4 k+1}{4 k-8 t+1} ; x_{2}^{Z}=\frac{-2(t-1)}{4 k-8 t+1} \\
\pi_{1}^{Z} & =-\frac{\left(4 k^{2} t^{2}+8 k^{2} t+4 k^{2}-28 k t^{2}-28 k t+49 t^{2}\right)}{2(4 k-8 t+1)^{2}} ; \pi_{2}^{Z}=\frac{2 k(t-1)^{2}(4 t-k)}{(4 k-8 t+1)^{2}} \\
W^{Z} & =\frac{(1-t)\left(8 k^{2} t+8 k^{2}-16 k t^{2}-44 k t+4 k+56 t^{2}-7 t\right)}{2(4 k-8 t+1)^{2}} .
\end{aligned}
$$

In the rest of the analysis, we will assume that $k \in(0.8 ; 1.2)$ and $t>$ 2.5. This assumption ensures, in the three regimes, both the second order conditions of the SPE and positive values for all the endogenous variables at the SPE. ${ }^{7}$

\section{Comparing the three regimes}

In this section we consider the comparisons among the main variables in the three regimes. In order to help the understanding of the basic intuitions of our welfare results that we show in Subsection 5.3, we illustrate graphically some comparative statics regarding quality, advertising and audience shares between the mixed and the zero duopoly in Subsection 5.1, and between the mixed and the private duopoly in Subsection 5.2.

\subsection{Mixed versus Zero Duopoly}

The Figures 1, 2 and 3 illustrate the comparisons among equilibrium variables in the mixed and the zero duopoly in the case in which the advertising is neutral, $k=1$. The rest of the cases follow a similar pattern.

Note, first, that the advertising level of the private platform in the zero duopoly is lower than the advertising level of each platform in the mixed duopoly. This is because advertising levels are strategic complements and the public platform does not set advertising in the zero duopoly.

\footnotetext{
${ }^{7}$ In particular if $k>0.7$ and $t>2$ then the second order conditions of SPE are ensured in the mixed duopoly, while $t>2.5$ an $k<1.2$ ensures that $v_{1}^{M}>0$. Finally, $k>0.8$ ensures that $a_{1}^{M}>0$.
} 


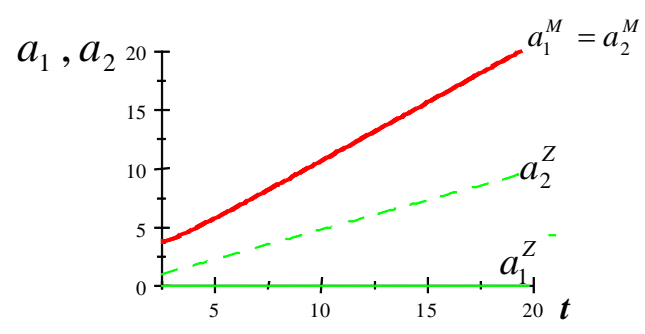

Figure 1: Advertising $k=1$

Regarding quality levels, Figure 2 shows that the sign of the quality differential between both platforms is reversed when we shift from the conventional mixed duopoly to the zero duopoly. While in the mixed duopoly the private platform provides higher quality, in the zero duopoly we get the opposite result. As a consequence, given that only the private platform provides advertising in this latter case, the public platform obtains a greater market share than the private platform at the SPE. Note, also that in the mixed duopoly both differentials are decreasing and very sensitive with $t$ while in the zero duopoly those differentials are almost independent of $t$.

Intuitively, under the mixed duopoly, the advertising undertaken by the public platform tends to increase the audience of the private platform, which in turn increases the profitability of its investment in quality. As a result, the SPE quality by the private platform is greater than the quality chosen by the public platform. In contrast, in the zero duopoly, the absence of advertising by the public platform tends to reduce the audience of the private platform, which reduces its incentive to invest in quality and explains the greater quality of the public platform at the SPE. Notice that the commitment of the publicly-owned platform to set zero ads makes it a tougher competitor for the private platform.

\subsection{Mixed versus Private Duopoly}

First, let us consider the case where advertising is neutral with respect to welfare $(k=1)$. The comparisons between the mixed and private duopoly in this case is illustrated in Figures 4, 5, and 6. Note that in both regimes the private and public platforms provide the same level of advertising and that 


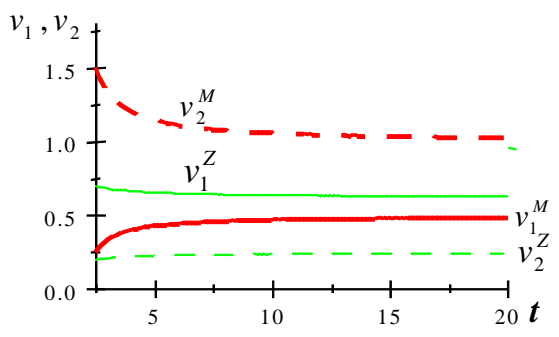

Figure 2: Quality $k=1$

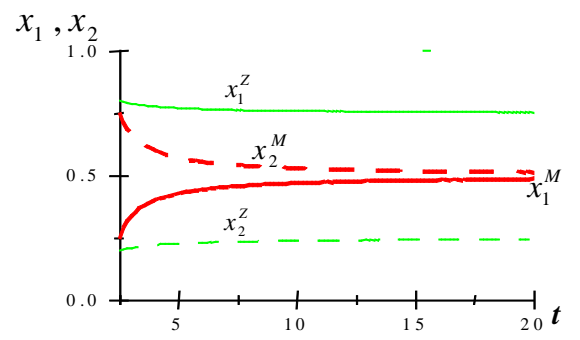

Figure 3: Audience shares $k=1$ 


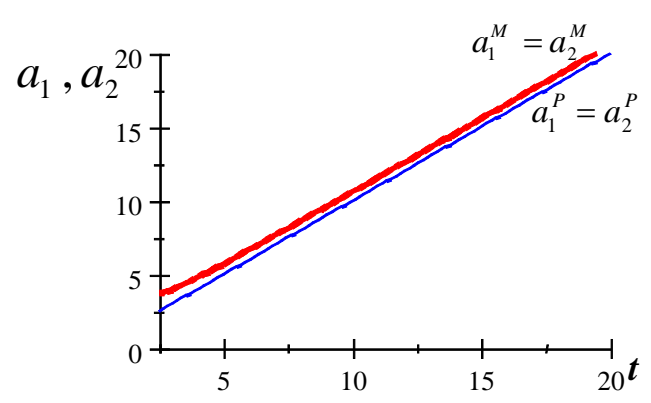

Figure 4: Advertising $k=1$

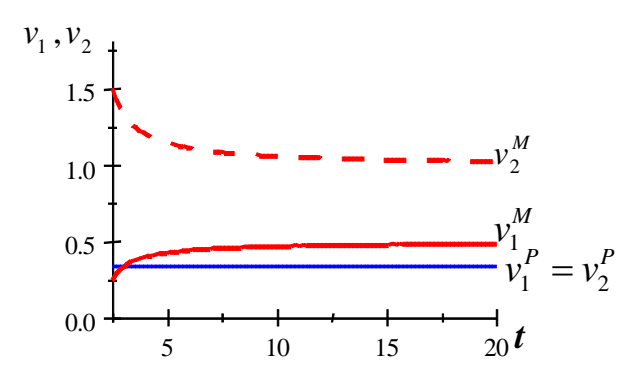

Figure 5: Quality $k=1$

this level is similar in both regimes. Moreover, advertising is increasing in $t$. Note also, that while in the private duopoly both platforms provide the same quality and audience share, in the mixed duopoly the private platform provides higher quality and in consequence it obtains higher audience share. However these differences are decreasing in $t$. Intuitively, advertising levels are increasing with $t$ because the platforms take advantage of the greater market power associated to an increased degree of product differentiation, which in turn is associated to a reduced incentive to provide a high differential quality by platforms in the mixed duopoly.

Now, let us consider the case where advertising is socially harmful. In particular, Figures 7, 8 and 9 illustrate the comparisons among the mixed and private regimes with $k=0.9$. Note that in contrast with the previous 


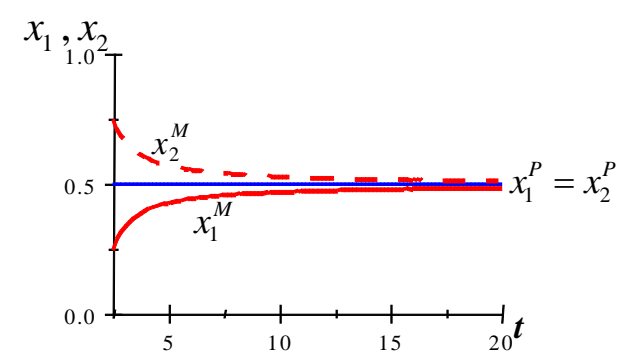

Figure 6: Aundience shares $k=1$

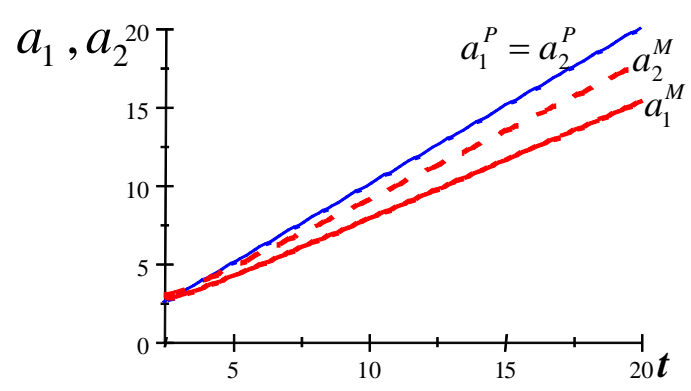

Figure 7: Advertising $k=0.9$

case, the advertising levels are smaller in the mixed duopoly for sufficiently large $t$. Moreover this difference is increasing in $t$. Note also that the public platform always sets lower level of advertising than the private platform in the mixed duopoly and this difference is increasing in $t$. Intuitively the public platform tends to reduce the socially harmful advertising. As a result, for $t$ large the public platform obtains higher audience share than the private one despite of the fact that it provides lower quality level.

Finally, Figures 10, 11 and 12 illustrate the previous comparisons when advertising is socially beneficial, assuming $k=1.1$. The main difference with respect to the previous cases is that the advertising levels in the mixed duopoly are greater than in the private one. Moreover the publicly-owned platform provides higher level of advertising than its private competitor. This 


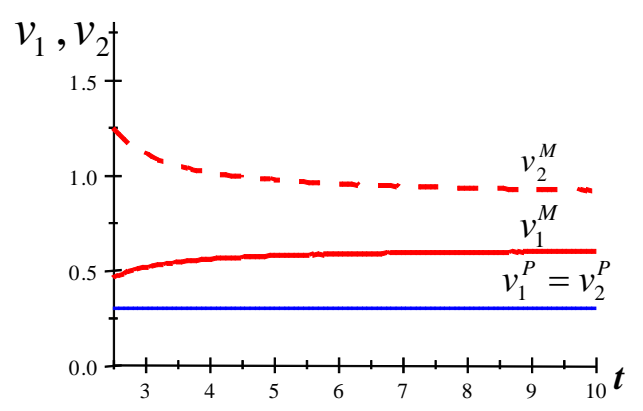

Figure 8: Quality $k=0.9$

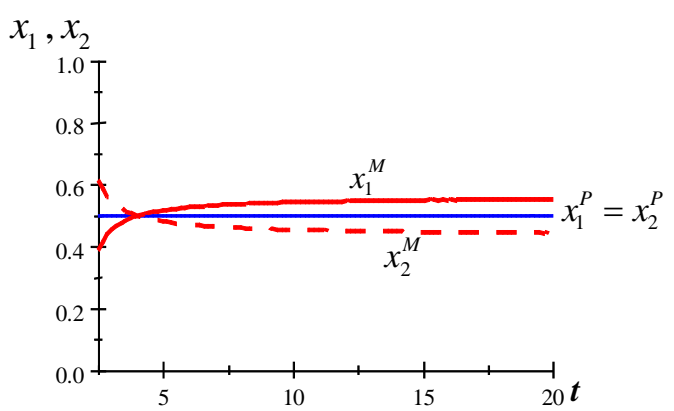

Figure 9: Audience shares $k=0.9$ 


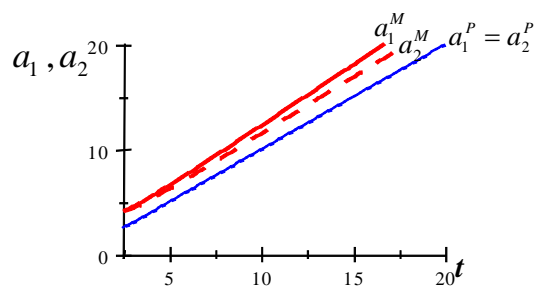

Figure 10: Advertising $k=1.1$

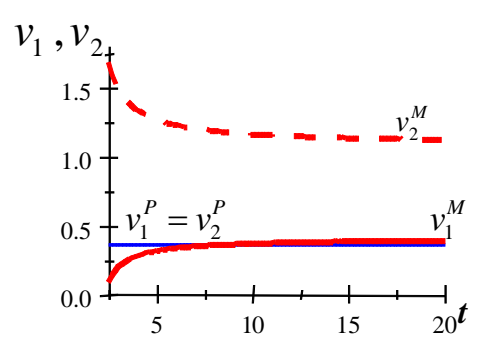

Figure 11: Quality $k=1.1$

pattern is explained by the fact that the public platform tends to increase the socially beneficial advertising.

\subsection{Welfare comparisons}

In this subsection we compare the social welfare obtained in the three regimes. First, we compare social welfare in the mixed and the zero duopoly. This comparison is illustrated in Figure 13, where $W^{Z}>W^{M}$ in region $Z$ and $W^{M}>W^{Z}$ in region $M$. According to Figure 13, when advertising is very harmful the zero duopoly is always better than the conventional mixed duopoly, from the social welfare point of view. Otherwise, the conventional mixed duopoly can be socially preferred, as stated in the following proposition.

Proposition 1 In the comparisons between the mixed and zero duopoly, we obtain that there exists a critical value of $k$ defined as $k^{*}(t)$, that is decreasing 


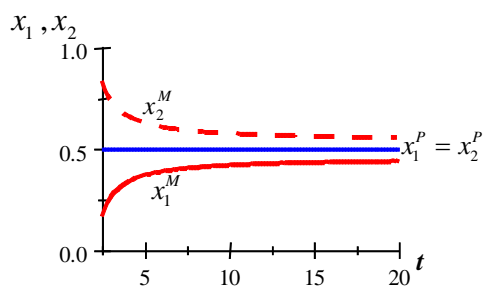

Figure 12: Audience shares $k=1.1$

in $t$, such that for $k \leq k^{*}(t)$ the zero duopoly is socially better (see region $Z$ ) and for $k \geq k^{*}(t)$ the mixed duopoly is socially better (region $M$ ).

Intuitively, the more harmful advertising is, the more likely is that the government commitment to zero advertising is the optimal policy. Additionally, when $t$ is small, quality differentiation is more important than horizontal differentiation. Therefore, the smaller is $t$, the more likely is that the optimal policy is the government commitment to zero advertising because this ensures a large audience for the tv-platform providing the highest quality. To see this, note that in the zero duopoly the publicly-owned platform provides the highest quality and obtains a very high audience share (see Figures 1, 2 and 3 ). Notice that the zero duopoly can be socially better even if advertising is socially desirable (that is, $k>1$ ) when the degree of horizontal differentiation is low enough. In particular, if $t<3.75$, we have that $k^{*}(t)>1$ which implies that $W^{Z}>W^{M}$ for some $k>1$.

Note that an interesting policy implication of this result is that an advertisingfree public platform (the zero duopoly) tends to be optimal as far as its content is sufficiently similar to the content provided by its private competitor (see the low values for $t$ in Figure 13), except in the cases where the social value of advertising is very high.

The comparison between the mixed and private duopoly is illustrated in Figure 14, where $W^{M}>W^{P}$ in regions $M_{1}$ and $M_{2}$, while $W^{P}>W^{M}$ in region $P$. By comparing the mixed and private duopoly, we find that the private duopoly is optimal when advertising is neutral, i.e. when $k$ is near to 1. However, when the negative or positive direct net effect of advertising is large enough, this result can be reversed, as illustrated in Figure 14 and the following proposition. 


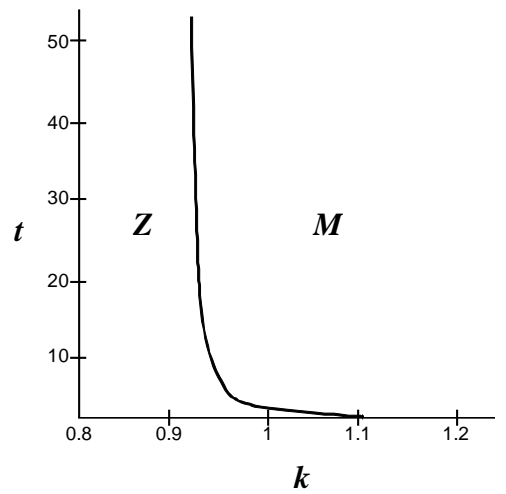

Figure 13: Mixed and Zero-advertising Duopoly

Proposition 2 In the comparisons between mixed and private duopoly, we obtain the following:

(i) for small values of $t$, the mixed duopoly is socially better if $k$ is low enough, but it is worse if $k$ is high enough;

(ii) for high values of $t$, private duopoly is better for intermediate values of $k$, but for extreme values of $k$ the mixed duopoly is better.

Note that according to Figure 14 if advertising is neutral $(k=1)$ private duopoly is always better than the mixed duopoly. ${ }^{8}$ However, when advertising is not neutral, a government's intervention through the ownership of a tv-platform is desirable if $t$ is large enough. Moreover, as $t$ increases, the intermediate interval in which privatization is optimal becomes narrower. The intuition of this result can be explained by comparing the level of advertising between both regimes. In particular, if advertising is socially harmful $(k<1)$ the mixed duopoly provides lower levels of advertising than the private duopoly for large enough values of $t$ (see Figure 7 ). Therefore, in this case a mixed duopoly is socially better than the private one because it reduces the negative welfare effects of advertising. By a similar argument, if advertising is socially beneficial $(k>1)$, the mixed duopoly is socially better than the private duopoly for $t$ large enough because in this case the mixed

\footnotetext{
${ }^{8}$ Formally, this particular case resembles the result obtained by Ishibashi and Kaneko (2008), by reinterpreting the advertising levels in our model as the prices levels in their model. However our formulation is more general because $k$ can be different from one, which implies that privatization is not always better than a mixed duopoly.
} 


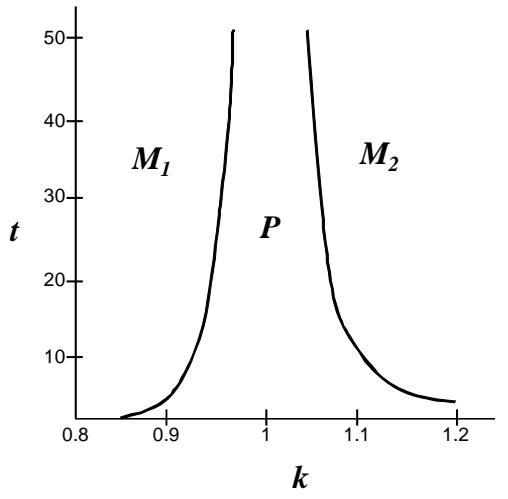

Figure 14: Mixed and Private duopoly

duopoly provides higher levels of advertising (see Figure 10). Note also that for $t$ small, the market shares differences between platforms are rather large in the mixed duopoly (see Figure 12) which in turn is associated with large quality differences (see Figure 11). Therefore, given that in this case advertising levels are similar in both regimes, welfare is greater in the private duopoly because it achieves an optimal distribution of market shares.

Note that our previous result suggests that those public platforms offering substantial differences in content with respect to their private competitors are more likely to play a beneficial role from the social welfare perspective. However a privatization policy tends to be optimal if the content provided by the publicly-owned platform is similar to that of its competitors, except when advertising is too harmful.

Now let us consider the optimal choice among the three previous regimes, which is gathered in the following proposition and illustrated in Figure 15, where $Z, P, M_{1}$ and $M_{2}$ indicate the optimal regime in each region.

Proposition 3 In the comparisons among the three regimes, we have the following:

(i) for small values of $t$, the optimal regime is the zero duopoly if $k$ is low enough (see region $Z$ ) and the private duopoly if $k$ is high enough (see region $P)$;

(ii) for intermediate values of t, the optimal regime is the zero duopoly if $k$ is small (see region $Z$ ), the private duopoly for intermediate $k$ (see region $P$ ) and mixed duopoly if $k$ is large (see region $M_{2}$ ); 


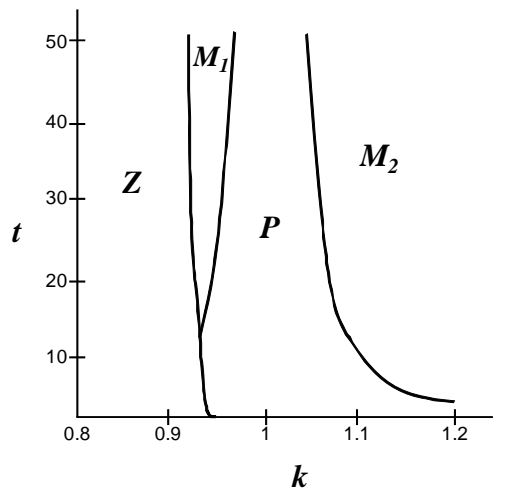

Figure 15: Mixed, Private and Zero-advertising Duopoly

(iii) for large values of $t$, the optimal regime is the zero duopoly if $k$ is small (see region $Z$ ), the mixed duopoly for intermediate-low and high levels of $k$ (see regions $M_{1}$ and $M_{2}$ ) and the private duopoly for intermediate-high levels of $k$ (see region $P$ ).

The basic intuitions behind this result are connected to the previous comparisons. In particular, let us consider case (ii) in Proposition 3. Broadly speaking, the zero duopoly is socially desirable when advertising is sufficiently harmful (region $Z$ ) because the absence of advertising by the public firm helps two objectives: first, to reduce the nuisance costs associated to advertising and, second, to increase the audience of the tv-platform with the highest quality. On the other extreme, when advertising involves a large positive net welfare effect (region $M_{2}$ ), the presence of a public platform is desirable but without the commitment to zero advertising. Finally, when advertising does not generate a large net welfare effect, the optimal policy is privatization (region $P$ ).

Note that our previous results (Propositions 2 and 3) suggests that those public platforms offering substantial differences in content with respect to their private competitors are more likely to play a beneficial role from the social welfare perspective. However a privatization policy tends to be optimal if the contents provided by the publicly-owned platform is similar to that of its competitors. 


\section{Conclusions}

In this paper we develop a model with a publicly-owned platform and a private one that compete in a free to air broadcasting market. The platforms are differentiated in two dimensions: content (horizontal differentiation) and quality (vertical differentiation). Assuming that each platform chooses its advertising and quality levels, we compare the equilibrium levels of quality, advertising and welfare under private and mixed duopoly competition. In this context, we also consider the effects on platforms' quality and on welfare of recent policies tending to eliminate advertising in the publicly-owned platforms. We show that the results are substantially different depending not only on the presence of a publicly-owned platform but also on the advertising restrictions on this platform.

One interesting insight from our analysis is that a government commitment to an advertising-free public platform can be socially desirable even if the direct effect of advertising is beneficial from the social welfare point of view (see Proposition 1 and Figure 13). The underlying explanation of this result is that besides the direct effect on welfare of advertising, there are also indirect effects associated to endogenous changes in quality and market shares. In particular, our results show that this case is associated to small degrees of horizontal platform differentiation. Thus a policy implication of this result is that an advertising-free public platform tends to be optimal as far as its content is sufficiently similar to the content provided by its competitor. However, eliminating advertising in the public platform can be suboptimal even if advertising is socially harmful. This case is associated with large levels of horizontal differentiation, as is also shown in Proposition 1. Therefore, the more differentiated is the content the weaker the case for an advertising-free public platform.

Our model also suggests some policy implications regarding the optimal choice between privatization or maintaining active public platforms. Basically, our results show that the case for privatization becomes weaker as the degree of horizontal differentiation becomes greater and advertising is not neutral (see Propositions 2 and 3). This result suggests that those public platforms offering substantial differences in content with respect to their competitors are more likely to play a beneficial role from the social welfare perspective. 


\section{Appendix}

In this section we incorporate a first stage in which the government sets the tax on the revenue of the rival private platform for financing the publiclyowned platform. Thus, we consider that the revenue obtained by the private platform consists of the advertising revenue after tax, and the revenue obtained by the publicly-owned platform consists of the tax revenue collected from the private one. So profits are given, respectively, by

$$
\pi_{1}=\tau \gamma a_{2} x_{2}-\frac{v_{1}^{2}}{2} ; \quad \pi_{2}=(1-\tau) \gamma a_{2} x_{2}-\frac{v_{2}^{2}}{2},
$$

where $\tau$ represents the direct tax over private platform's revenue. By substituting the demand function (2) in the definition of profits and taking into account that $a_{1}=0$, we can obtain:

$$
\pi_{1}=\tau \gamma a_{2} \frac{v_{2}-v_{1}+t-\delta a_{2}}{2 t}-\frac{v_{1}^{2}}{2} ; \quad \pi_{2}=(1-\tau) \gamma a_{2} \frac{v_{2}-v_{1}+t-\delta a_{2}}{2 t}-\frac{v_{2}^{2}}{2} .
$$

From maximizing private platform's profit, we can obtain the level of advertising by the private platform 2, which is (18). By substituting it in the profit functions (22) we obtain the market shares and profits:

$$
\begin{array}{ll}
x_{1}=\frac{v_{1}-v_{2}+3 t}{4 t} ; & \pi_{1}=\tau \frac{k\left(v_{2}-v_{1}+t\right)^{2}}{8 t}-\frac{v_{1}^{2}}{2} ; \\
x_{2}=\frac{v_{2}-v_{1}+t}{4 t} ; & \pi_{2}=(1-\tau) \frac{k\left(v_{2}-v_{1}+t\right)^{2}}{8 t}-\frac{v_{2}^{2}}{2} .
\end{array}
$$

We now consider the quality choice by platforms, so the publicly-owned platform maximizes the social welfare and the private one maximizes her/his profit. Taking into account that the social welfare $(W)$ at the first stage is now given by (19), from the first order conditions in the first stage of the game, we can obtain the reaction function of each platform:

$$
v_{1}\left(v_{2}\right)=\frac{(2 k-7) t+(2 k+1) v_{2}}{2 k-8 t+1} ; \quad v_{2}\left(v_{1}\right)=\frac{(1-\tau)\left(t-v_{1}\right) k}{4 t+k(\tau-1)} .
$$

From the intersection of platforms' quality reaction function, we obtain the NE levels of advertising, market shares and profits at the second stage of this game:

$$
v_{1}(\tau)=\frac{2 k(1-\tau)+(2 k-7) t}{2 k(2-\tau)+1-8 t} ; \quad v_{2}(\tau)=\frac{2 k(\tau-1)(t-1)}{4 k-8 t-2 k \tau+1} ; \quad a_{1}(\tau)=0 ; \quad a_{2}(\tau)=\frac{-4 t(t-1)}{(1+2 k(2-\tau)-8 t) \delta}
$$




$$
\begin{gathered}
x_{1}(\tau)=-\frac{6 t-4 k+2 k \tau+1}{4 k-8 t-2 k \tau+1} \quad x_{2}(\tau)=\frac{-2(t-1)}{4 k-8 t-2 k \tau+1} \quad \pi_{2}(\tau)=\frac{2 k(1-\tau)(t-1)^{2}(4 t-k+k \tau)}{(4 k-8 t-2 k \tau+1)^{2}} . \\
\pi_{1}(\tau)=-\frac{4 k^{2} t^{2}-8 k^{2} t \tau+8 k^{2} t+4 k^{2} \tau^{2}-8 k^{2} \tau+4 k^{2}-16 k t^{3} \tau+32 k t^{2} \tau-28 k t^{2}+12 k t \tau-28 k t+49 t^{2}}{2(4 k-8 t-2 k \tau+1)^{2}} \\
W(\tau)=-\frac{(t-1)\left(\left(4 t \tau^{2}-8 t \tau+8 t-8 \tau+8\right) k^{2}-16 k t^{2}+32 k t \tau-44 k t-4 k \tau+4 k+56 t^{2}-7 t\right)}{2(4 k-8 t-2 k \tau+1)^{2}}
\end{gathered}
$$

By maximizing the welfare function (23) with respect to the tax, we find that the optimal level of the tax is zero. ${ }^{9}$

$$
\frac{\partial W(\tau)}{\partial \tau}=-2 k(2 k \tau+1)(t-1)^{2} \frac{8 t-2 k-1}{(8 t-2 k(2-\tau)-1)^{3}}<0
$$

\section{References}

[1] Alcock, J. and G. Docwra, 2005, A Simulation Analysis of the Market Effect of the Australian Broadcasting Corporation, Information Economics and Policy, 17 (4), 407-427.

[2] Anderson, S. P., 2007, Regulation of Television Advertising, in Paul Seabright and Jurgen Von Hagen, Editors, The Economic Regulation of Broadcasting Markets, Cambridge University Press.

[3] Anderson, S. P. and S. Coate, 2005, Market Provision of Broadcasting: A Welfare Analysis, Review of Economic Studies, 72, 947-972.

[4] Anderson, S. P. and J. J. Gabszewicz, 2006, The Media and Advertising: A Tale of Two-sided Markets, in Victor A. Ginsburgh and David Throsby, Editors, Handbook of the Economics of Art and Culture, Volume 1, Elsevier B.V.

[5] Armstrong, M., 2005, Public Service Broadcasting, Fiscal Studies, 26 (3), 281-299.

\footnotetext{
${ }^{9}$ We do not consider the possibility of subsidies for the private platform.
} 
[6] Beard, T. R., R. B. Ekelund Jr., G. S. Ford and R. S. Saba, 2001, Price-Quality Tradeoffs and Welfare Effects in Cable Television Markets, Journal of Regulatory Economics, 107-123.

[7] Bel, G. and L. Domènech, 2009, What Influences Advertising Price in Television Channels?: An Empirical Analysis on the Spanish Market, Journal of Media Economics, 22 (3), 164-183.

[8] Chu, Ch. S., 2010, The effect of satellite entry on cable television prices and product quality, RAND Journal of Economics, 41 (4), 730-764.

[9] Coase, R., 1966, The economics of broadcasting and government policy, American Economic Review, 56, 440-447.

[10] Crampes, C., C. Haritchabalet and B. Jullien, 2009, Advertising, Competition and Entry in Media Industries, The Journal of Industrial Economics, 57 (1), 7-31.

[11] Gabszewicz, J. J., D. Laussel and N. Sonnac, 2004, Programming and Advertising Competition in the Broadcasting Industry, Journal of Economics and Management Strategy, 13 (4), 657-669.

[12] Gantman, N. and O. Shy, 2007, Broadcasting Competition and Advertising Quality: A Two-sided Market Approach, mimeo.

[13] González-Maestre, M. and F. Martínez-Sánchez, 2010, The Role of Program Quality and Publicly-owned Platforms in the Free to Air Broadcasting Industry, IVIE Working Papers Serie AD 2010-19.

[14] Imbs, J., H. Mumtaz, M. O. Ravn, and H. Rey, 2010, One TV, One Price?, The Scandinavian Journal of Economics, 753-781.

[15] Ishibashi, K. and T. Kaneko, 2008, Partial Privatization in Mixed Duopoly with Price and Quality Competition, Journal of Economics, 95 (3), 213-231.

[16] Kind, H. J., T. Nilssen and L. Sørgard, 2007, Competition for Viewers and Advertisers in a TV Oligopoly, Journal of Media Economics, 20 (3), 211-233. 
[17] Lin, P., 2011, Market provision of Program Quality in the Television Broadcasting Industry, The B.E. Journal of Economic Analysis 86 Policy: Vol. 11: Iss. 1 (Contributions), Article 17.

[18] Peitz, M. and T. M. Valletti, 2008, Content and Advertising in the Media: Pay-tv versus Free-to-air, International Journal of Industrial Organization, 26, 949-965.

[19] Stühmeier, T. and T. Wenzel, 2011, Regulating Advertising in the Presence of Public Service Broadcasting, mimeo.

[20] Wilbur, K. C. (2008), A Two-Sided, Empirical Model of Television Advertising and Viewing Markets, Marketing Science, 27 (3), 356-378. 


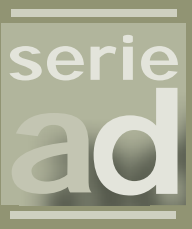

\section{I vie}

Guardia Civil, 22 - Esc. 2, 1o

46020 Valencia - Spain

Phone: +34963190050

Fax: +34 963190055

Department of Economics

University of Alicante

Campus San Vicente del Raspeig

03071 Alicante - Spain

Phone: +34965 903563

Fax: +34965903898

Website: www.ivie.es

E-mail: publicaciones@ivie.es 